REVISTA X, Curitiba, volume 12, n.1, P. 160-177,2017.

\title{
MORANGO OU TUTTI-FRUIT? UMA PROPOSTA DE SEQUÊNCIA BÁSICA DO LETRAMENTO LITERÁRIO PARA A GUERRA DO CHICLETE, DE MIGUEL SANCHES NETO
}

\section{Strawberry or Tutti Fruit? A Basic Sequence of The Literary Literacy for $\boldsymbol{A}$ Guerra do Chiclete, By Miguel Sanches Neto}

\author{
Rejane Aguiar da SILVA - UTFPR ${ }^{1}$ \\ Zenaide NEGRÃO - UTFPR ${ }^{2}$ \\ Rogério BORTOLIN - UTFPR ${ }^{3}$ \\ Alessandra DUTRA - UTFPR ${ }^{4}$ \\ Marilu MARTENS - UTFPR ${ }^{5}$ \\ Evandro de Melo CATELÃO - UTFPR ${ }^{6}$
}

RESUMO: O presente trabalho tem por objetivo apresentar uma prática docente de letramento literário por meio do livro A Guerra do Chiclete, do escritor Miguel Sanches Neto (2014), com a aplicação da sequência básica proposta por Rildo Cosson (2014) e das produções textuais do alunado decorrentes da interação com o texto literário. Especificamente, o foco da pesquisa-ação consiste na aplicação de um projeto de leitura numa turma de sexto ano do Ensino Fundamental II, objetivando sistematizar prática de leitura motivacional que gere resultados satisfatórios quanto à interpretação da obra literária. Ainda sob o ponto de vista teórico, busca-se entender as produções textuais dos estudos sociodiscursivos de Bronckart (2006) e Marcuschi (2011), e em que medida o trabalho com o texto literário pode corroborar a aquisição de múltiplas linguagens pelos discentes. Por fim, no intuito de validar a sequência didática utilizada, serão apresentadas algumas produções realizadas.

PALAVRAS-CHAVE: A guerra do chiclete; Letramento Literário; Sequência Básica; Literatura; Ensino.

ABSTRACT: This paper aims to present a teaching practice of literary literacy through the reading of the book A Guerra do Chiclete, by Miguel Sanches Neto (2014), with an application of a basic sequence, proposed by Rildo Cosson (2014), and the writing

\footnotetext{
${ }^{1}$ Mestranda em Ensino de Ciências Humanas pela Universidade Tecnológica Federal do Paraná; professora das redes estadual e particular de ensino no estado do Paraná.

${ }^{2}$ Especialista em Teoria da Literatura e Literatura Comparada pela Faculdade de Filosofia, Ciências e Letras de Guarapuava-PR.; atualmente é docente da Universidade Tecnológica Federal.

${ }^{\text {E }}$ Especialista em Língua Inglesa pela Universidade Norte do Paraná; professor de Português, Inglês e Literatura do Colégio Monteiro Lobato.

${ }^{4}$ Doutora em Linguística e Língua Portuguesa pela UNESP/Araraquara; atualmente, é professora adjunta da Universidade Tecnológica Federal do Paraná - Campus de Londrina.

${ }^{5}$ Doutora em Letras (UNESP); atualmente é professora titular da Universidade Tecnológica Federal do Paraná.

${ }^{6}$ Doutor em Estudos Lingüísticos pela Universidade Federal do Paraná; Professor do Magistério Superior da Universidade Tecnológica Federal do Paraná.
} 
REVISTA X, Curitiba, volume 12, n.1, P. 160-177,2017.

production of Elementary School students from the interaction with the text. The focus of this action research consists of an application of a reading project within a sixth grade class, intending to systematize the motivational reading practice engendering satisfactory results on the interpretation of this literary work. Still through this theoretical approach, it pursues the comprehension of the writing productions from the social-discursive studies by Bronkart (2006) and Marcuschi (2011), and how the work with the literary text can enhearse the students multiple languages acquisition. Finally, intending to ratify the basic sequence some productions done by the students will be presented.

KEY WORDS: A guerra do chiclete; Literary Literacy; Basic Sequence; Literature; Teaching.

\section{INTRODUÇÃO}

Ao professor de Língua Portuguesa é comum a indagação sobre a melhor estratégia ou busca por uma forma mais profícua e atualizada no trabalho com o texto literário, principalmente no Ensino Fundamental, quando grande parte dos alunos demonstra o interesse pela leitura. O papel do educador, portanto, é manter o contato efetivo dos estudantes com a obra, à medida que muito da ludicidade dos textos com que tiveram contato nos anos anteriores é substituída por textos mais densos e, logo, mais desafiadores para o leitor em processo.

Desta forma, trabalhar a experiência da leitura literária no contexto do Ensino Fundamental é um desafio e exige estratégias para que ela possa ser compreendida, visto que auxilia na formação das inúmeras competências a que estão vinculadas: a interpretação das linguagens, a aquisição vocabular, a criticidade sem, no entanto, perder aquilo que lhe é peculiar: a literariedade.

Assim, quando pensado para o ambiente escolar, o trabalho com a literatura precisa contemplar uma sistematização concreta, com a formação e a habilitação do leitor via contato direto com o texto enquanto expressão de arte, ao mesmo tempo que compreende a leitura literária enquanto prática e objeto de reflexão social que colabora para a humanização do sujeito, segundo Antonio Candido (1995, p.175) "ela [a leitura literária] atua em grande parte no subconsciente e inconsciente".

Partindo de tais pressupostos didáticos com o texto literário, é importante postular que, quando usado como apêndice para o ensino de Língua Portuguesa e seus aspectos gramaticais, a escolarização da literatura é inválida, pois desvincula o texto do 
REVISTA X, Curitiba, volume 12, n.1, P. 160-177,2017.

seu caráter artístico e humanizador. Nas palavras de Cosson (2014, p. 23): “[...] a literatura não está sendo ensinada para garantir sua função essencial de construir e reconstruir a palavra que nos humaniza". Nesse aspecto, o presente trabalho pretende apresentar uma prática engajada com o aspecto humanizador e sociodiscursivo da literatura.

Não é errôneo afirmar que grande parte dos professores atuantes na rede básica de ensino não receberam formação voltada ao letramento literário, ou ainda têm dificuldade em promover práticas de leituras que englobem, além da compreensão dos textos, produções textuais que estejam embasadas em aspectos sócio-discursivos relevantes.

Estes conteúdos estão, pois, presentes nos Planos de Trabalho Docentes, porém pouco explorados no real contexto escolar. Relativamente novo, oriundo do inglês literacy, o termo letramento significa, na prática escolar, de acordo com Soares (2012, p.58) na obra Letramento: um tema em três gêneros: "levar os indivíduos a fazer uso da leitura e da escrita, envolver-se em práticas sociais de leitura e de escrita”. Sob tal ótica, o termo "letramento literário", quando aplicado ao ensino de literatura, revela ainda mais estranhamento e a proposta de trabalho com gêneros discursivos torna-se ainda mais desafiadora, ao passo que a barreira do desconhecimento dos temas é perceptível.

Diversas são as publicações sobre as teorias e as práticas de leitura realizadas por pesquisadores e educadores com o texto literário. No entanto, para A Guerra do Chiclete, de Sanches Neto (2014), optamos por utilizar como suporte teórico o letramento literário, doravante LL, na modalidade da Sequência Básica proposta por Cosson (2014), em Letramento Literário: Teoria e Prática.

A escolha dessa obra explica-se devido à sua contemporaneidade, no aspecto do tempo de produção e publicação, mas que remete a um tempo passado. Outro fator que contribuiu para tal opção foi o fato do autor ser paranaense - mesma localidade onde a pesquisa foi aplicada. Assim, pretendeu-se, neste estudo, diminuir a distância temporal/ espacial entre autor e sua produção, ao leitor - neste contexto, consumidor da obra literária. As atividades aqui descritas e analisadas foram aplicadas em uma turma de $6^{\circ}$ ano, em um colégio particular da cidade de Arapongas, Paraná. O livro foi adotado e as atividades foram realizadas durante o segundo bimestre letivo do ano de 2016.

Esse encaminhamento didático-metodológico propõe a compreensão de que o texto literário no ambiente escolar busca "reformar, fortalecer e ampliar a educação literária que se oferece no ensino básico" (COSSON, 2014, p.12). Logo, calcou-se a 
REVISTA X, Curitiba, volume 12, n.1, P. 160-177,2017.

prática na sequência básica composta por quatro passos: motivação (preparar os leitores), introdução (apresentar leitor e obra), leitura (contato com o texto) e interpretação (inferências) (COSSON, 2014). Cumprida cada uma das etapas, foi possível acrescentar a produção textual de vários gêneros, bem como compartilhar tais experiências com a organização de exposições dos trabalhos apresentados. Ao estabelecer os passos das sequências, as práticas possibilitam a fruição da leitura literária em sala de aula, fundamental ao processo educativo. A sequência básica aqui descrita como uma pesquisa-ação é, portanto, uma das inúmeras possibilidades de leitura motivadora do texto literário nas escolas brasileiras.

Durante o planejamento do trabalho com o livro Guerra de Chicletes, tais aspectos acima descritos foram considerados primordiais para atestar a validade da intervenção em sala de aula. Justifica-se a escolha pela sequência proposta por Cosson (2014), pois a fácil compreensão dos temas e sequências apresentados pelo autor podem servir como ponto de partida para suprir a carência teórico-metodológica do professorado. Assim, o objetivo desse estudo é apresentar resultados da aplicação teórica em sala de aula para a formação de leitores, avançando rumo à humanização e ao letramento literário.

\section{AGIR DE LINGUAGEM E LETRAMENTO LITERÁRIO}

Ao entender que o homem é o único ser que se comunica por meio da estruturação de códigos linguísticos, estudos sócio-discursivos mais recentes de Bronckart (2006) discutem o agir de linguagem que, segundo ele, são as ações de ordem sociológica e psicológica que promovem as produções de textos, os quais são os correspondentes empíricos linguísticos das atividades de linguagem. Advindos dos textos, têm-se os gêneros textuais, que de acordo com Marcuschi (2008, p. 55) são a "materialização dos textos em situações comunicativas recorrentes" que circulam em determinados domínios discursivos, entendidos por ele enquanto "práticas discursivas nas quais podemos identificar um conjunto de gêneros textuais que às vezes lhes são próprios ou específicos” (p. 155). Partindo destes pressupostos, considera-se que a comunicação humana se estabelece e que a produção de textos orais e escritos se efetiva.

Dentre as mais diversas formas de expressão do homem, a literatura - que tem a linguagem como matéria - é uma das que permeia o imaginário, com a subjetividade e a 
REVISTA X, Curitiba, volume 12, n.1, P. 160-177,2017.

criatividade do homem. Sob tal ótica, os aspectos comuns aos textos considerados literatura são:

[...] as criações de toque poético, ficcional, ou dramático em todos os níveis de uma sociedade, em todos os níveis de cultura desde que chamamos de folclore, lenda, chiste, até as formas mais complexas e difíceis da produção escrita das grandes civilizações (CÂNDIDO, 1995, p. 174).

As questões sobre literariedade do texto, todavia, são mais complexas do que a afirmação aqui exposta. Ao que, vale lembrar, é pressuposto para a escolha do texto literário, em sala de aula, o cabedal de leituras do professor, além da necessária compreensão do aspecto literário da obra escolhida para evitar o risco de invalidar a proposta didática, sob o questionamento de como tornar a leitura da narrativa de Sanches Neto (2014) significativa para os alunos, em elemento de reflexão e transformação de seus saberes e vivências. Para avançar rumo ao LL, algumas atividades lúdicas possibilitaram a escritura de gêneros diversificados. Assim, seguindo a teoria de Marcuschi (2002), foram solicitados verbetes e cartazes para que a sequência básica sugerida por Cosson (2014) se efetivasse e o trabalho com a narrativa se tornasse atraente para os estudantes, instigando a leitura, releituras e possibilidades interpretativas.

Sendo, portanto, a literatura o reflexo mediato da (ou de uma) época/sociedade sob a ótica de um autor, variando, por conseguinte, de obra para obra e de época para época, levá-la para a sala de aula é promover o encontro dos alunos com um texto e uma linguagem diferente da cotidiana, como descrevem Wellek e Warren (1974),

[...] abundante em ambiguidades, homônimos e de categorias arbitrárias ou irracionais como o gênero gramatical, é permeada de acidentes históricos, por recordações e por associações. Numa palavra é uma linguagem <conotativa $>$. Acresce que a linguagem literária está longe de ser apenas referencial: tem o seu lado expressivo, comunica o tom e a atitude do orador ou do escritor (WELLEK; WARREN, 1974, p. 24).

O contato com o literário, cuja linguagem imaginária e ficcional é distinta da do dia a dia, proporciona aos alunos senso de pertencimento e humanização, uma vez que eles adentram no campo das fabulações - comum dos seres humanos - e podem se identificar com determinado enredo ou se colocar no lugar das personagens (ou eu lírico, no caso dos poemas). A reflexão também é potencializada, uma vez que o texto literário permite múltiplas interpretações, formas de expressões e de conhecimento (CANDIDO, 1995). 
REVISTA X, Curitiba, volume 12, n.1, P. 160-177,2017.

\section{PROCEDIMENTOS METODOLÓGICOS}

Tal estudo trata-se de uma pesquisa-ação, na qual são associados conhecimentos científicos com práticas de sala de aula, justamente por se configurar uma aplicação de um projeto de letramento literário em uma turma de $6^{\circ}$ ano do Ensino Fundamental. Ao seguir o encaminhamento metodológico proposto por Cosson (2014), a execução dessa prática ocorreu conforme expressa na tabela abaixo:

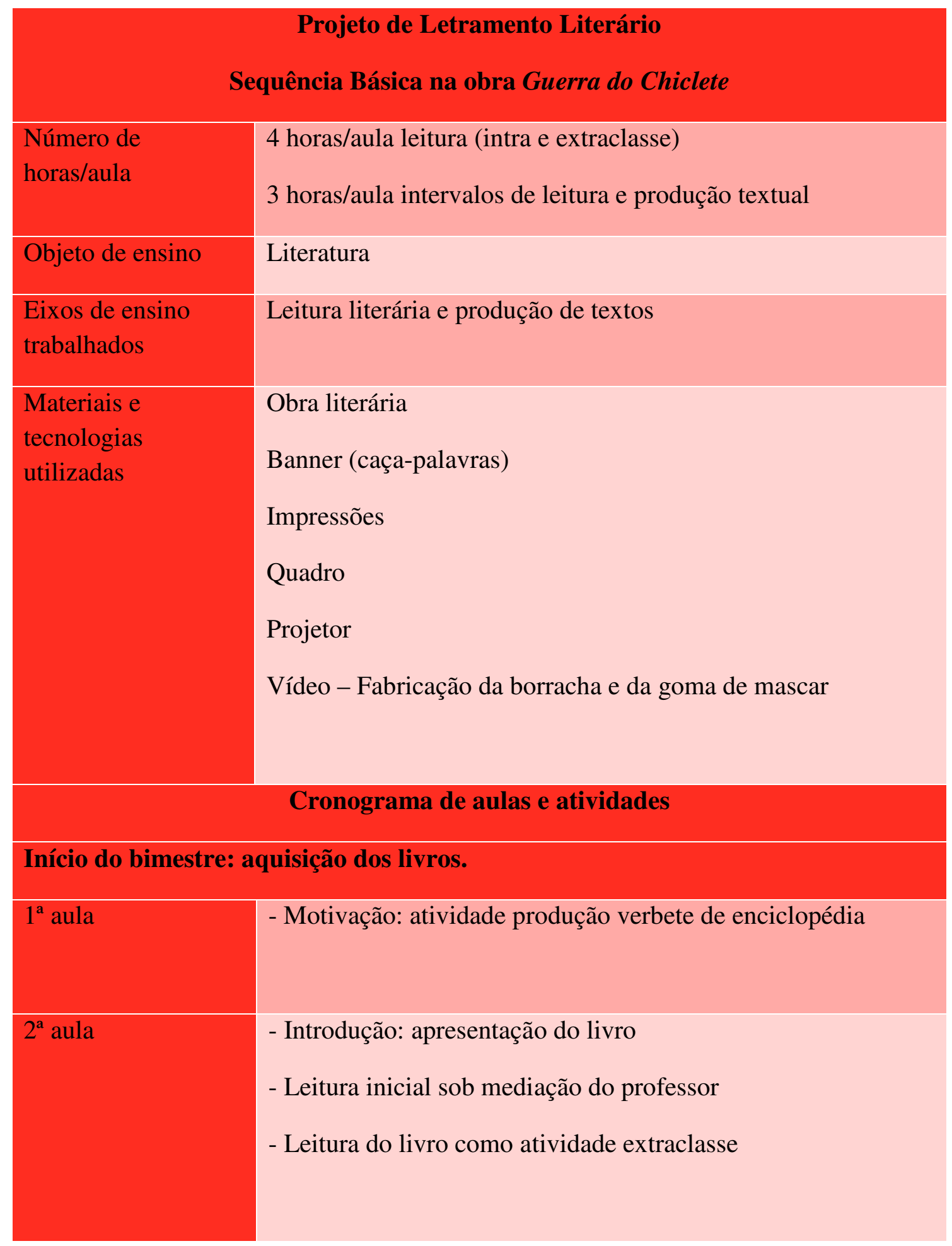


REVISTA X, Curitiba, volume 12, n.1, P. 160-177,2017.

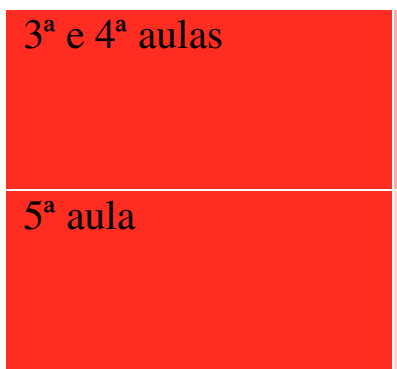

- Intervalo de leitura (banner caça-palavras)

- Debate com interpretação da obra em grupos

- Vídeo extração do látex e produção da borracha

- Interpretação (Produção final - gênero textual cartaz)

Tabela de planejamento para letramento literário (SILVA, 2016)

\subsection{Seleção dos participantes}

A escolha do $6^{\circ}$ ano para a execução dessa prática deu-se tanto pela sugestão de indicação de público disponibilizada pela própria editora responsável pela distribuição do livro, quanto pelo conteúdo, temática e linguagem dessa obra, adequados para tal faixa etária.

Com uma linguagem clara e sob um título antagônico ao contexto infantil, "guerra", pois está associada ao contexto de poder, violência e dominação do mundo adulto, e "chiclete", próprio do contexto infantil, Miguel Sanches Neto dá vida às personagens que vivem no contexto da Segunda Guerra Mundial. Trata-se, portanto, de uma história ambientada em tal período permitindo, de maneira inusitada e criativa, que os alunos compreendam os possíveis impactos daquela guerra no cotidiano das crianças e na sociedade brasileira da época.

\section{DESCRIÇÃO DAS ETAPAS}

Durante a aplicação a leitura do livro foi sistematizada - realizada extraclasse reservando uma aula semanal para a sua compreensão. A cada semana, novos objetivos e atividades foram realizadas em sala de aula. A validade da estratégia aqui tabulada, no entanto, é reconhecida perante a leitura, inferências e produções dos alunos que integram a prática.

Desta forma, segue-se o passo a passo da aplicação desse projeto que visava, sobretudo, a promoção do letramento literário.

\section{MOTIVAÇÃO}

Para Cosson (2014), as atividades de motivação podem garantir ou não o sucesso do encontro entre leitores e texto literário. É nesse momento que eles são preparados para receber a obra, não silenciando, no entanto, o texto, tampouco o aluno. Vale 
REVISTA X, Curitiba, volume 12, n.1, P. 160-177,2017.

ressaltar que as discussões propostas no momento da motivação pretendem considerar as intervenções e interpretações de todo o alunado, pois são relevantes para a compreensão da obra literária, bem como seus efeitos de sentido, seja para reiterá-los ou confrontá-los durante as etapas posteriores.

Já em posse dos livros há uma semana, os estudantes tiveram na primeira aula do projeto uma conversa informal norteada pelos seguintes questionamentos:

1) O que esperar de um livro que se chama A Guerra do Chiclete?

2) Quais motivos levam as pessoas ou países entrarem em guerra? O chiclete poderia ser um destes motivos (como é, por exemplo, o Petróleo)?

Debatidas as ideias, como atividade de produção escrita - necessária para registro da prática em desenvolvimento - foi solicitado que escrevessem um verbete de enciclopédia, criando assim uma história para a Guerra do Chiclete - como se ela realmente tivesse acontecido e tratada agora como fato histórico. $\mathrm{O}$ texto dos alunos deveria responder às seguintes perguntas:

- O que foi a Guerra do Chiclete?

- Quem dela participou?

- Onde aconteceu?

- Quando aconteceu?

- Como aconteceu?

- Por que aconteceu?

Por último, solicitou-se a ilustração do "fato histórico" criado por eles, e no fim da aula todos ganharam chicletes ${ }^{7}$. É válido ressaltar que a produção de tal gênero textual ocorreu após ele ter sido trabalhado previamente nas aulas de Produção de Texto e Língua Portuguesa. Portanto, os alunos já tinham contato e conhecimento prévio das especificidades de tal gênero. A contextualização temática foi verificada na produção dos verbetes realizada em sala de aula e teve como objetivo atestar o conhecimento sobre o assunto a ser abordado pela obra literária.

\section{INTRODUÇÃO}

\footnotetext{
${ }^{7}$ É válido ressaltar que deve-se observar a possibilidade de levar alimentos comestíveis em sala de aula. $\mathrm{Na}$ classe onde a pesquisa aqui descrita foi aplicada, não havia proibição sobre o consumo de chicletes por parte da direção da escola e nenhum dos alunos possui intolerância alimentar de glicose.
} 
REVISTA X, Curitiba, volume 12, n.1, P. 160-177,2017.

Houve a apresentação do livro para a turma e, o professor pesquisador conduziu uma breve análise semiótica sobre as possibilidades que levaram o ilustrador à escolha das cores presentes na capa e nas ilustrações do livro. Na sequência, levantaram-se hipóteses sobre o assunto do livro, com algumas contribuições dos alunos: o livro tratava de "uma briga causada por chicletes", "roubo do chiclete" ou "reivindicação pela liberação dos chicletes em uma escola".

Com as capas abertas, uma leitura semiótica foi realizada, chamando a atenção de todos para as diferenças de cor - analogia ao chiclete no início da mastigação (escuro) e no final (claro), e também a expressão de vitória dos meninos, sobre o tanque de guerra, na ilustração. Detalhes da vida do autor também foram explorados, principalmente o fato de ele ter nascido em uma cidade próxima a de que os alunos estavam. Isso chamou a atenção deles, deixando-os animados com a possibilidade de um dia conhecê-lo.

Norteados pelas asserções de Cosson (2014) sobre as atividades de introdução, os alunos foram levados a conhecer mais sobre o autor e entender o porquê de tal obra ter sido escolhida: trata-se de um autor local, também a temática da obra se faz relevante - ambientada durante a Segunda Guerra Mundial, explorou seus efeitos em um grupo de crianças brasileiras. Ressaltou-se a pequena "revolução" que elas fizeram frente ao problema enfrentado pela comunidade na qual estavam inseridas. Tais informações e discussões aconteceram por meio da exploração de elementos físicos do livro (capa) e leitura da sinopse (contracapa).

\section{Leitura coletiva e individual}

Encerrado o momento de discussão, foi realizada a leitura das duas primeiras páginas para a turma, atentando-se à entonação para demonstrar à classe o prazer que a leitura proporcionava.

Cosson (2014, p. 62) comenta que o professor, a partir desta atividade, deve acompanhar a leitura, sem confundir, porém, com policiamento, segundo o autor, convidando os alunos a apresentar o resultado das leituras durante os "intervalos", período que eles leem fora da sala de aula. Para a aula seguinte (uma semana depois), deveriam realizar a leitura integral da obra.

\section{INTERVALOS DE LEITURA}


REVISTA X, Curitiba, volume 12, n.1, P. 160-177,2017.

Quanto à abordagem metodológica trabalhada com a obra em questão, encontrase na fala de Tinoco (2013) um adendo às práticas de leitura literária que procuram estabelecer relação com as oficinas de produção textual, sob um viés dialógico e, como o próprio termo letramento sugere, que possibilite além da leitura e escrita, uma prática social:

\footnotetext{
Às intenções da linguagem escrita (técnica e literária) cabe [a escola] cumprir o papel, entre outros, de transformar a pessoa em leitor consciente na medida em que ele exerce a atividade de ler de maneira produtiva (produzindo conhecimento adquirido) e reveladora (revelando informações culturais, sociais[...]); na medida em que, mais que a obra, ele lê, por meio dela o(s) mundo(s) do autor e dele próprio, leitor (TINOCO, 2013, p.140)
}

Assim, os intervalos de leitura constituíram a quarta e última etapa da sequência, a interpretação. Nesses momentos foram propostas atividades que fizessem sentido dentro do contexto social do alunado, atribuindo ao leitor a tarefa de produtor de textos.

Usando de artifícios lúdicos e de faz de conta, os intervalos de leitura procuraram levar os discentes à interação com a temática da obra. No primeiro momento, escreveram um verbete de enciclopédia, somente a partir do título da narrativa. As atividades de produção realizadas na sequência foram importantes à medida que descortinaram a compreensão do texto. As produções, portanto, devem contemplar o diálogo entre o leitor e a obra, conferindo valor à leitura realizada.

Para instigar a interpretação, o professor confeccionou e fixou no quadro um caça-palavras em formato de banner, no tamanho de 100 x $80 \mathrm{~cm}$, no qual os alunos deveriam encontrar palavras presentes na obra.

Em seguida, em duplas, os alunos ficaram responsáveis por um ou dois termos que deveriam definir e explicar em relação à narrativa. Para tal atividade, puderam fazer uso de dicionários, de livros, da internet, pois o trabalho se estendeu para a aula da semana seguinte quando uma discussão foi levantada e eles fizeram a relação entre os significados e a obra, compreendendo melhor enredo e fatos históricos, sanando também suas dúvidas com relação à narrativa.

Sob a perspectiva de Cosson (2014, p.27), segundo o qual "a leitura é um ato solitário, mas a interpretação é um ato solidário", tal atividade permitiu o compartilhamento de interpretações, perspectivas e dúvidas dos alunos e os trechos em que tiveram dificuldades. Diferentes opiniões sobre o enredo e o final da narrativa 
REVISTA X, Curitiba, volume 12, n.1, P. 160-177,2017.

também foram discutidas. Dessa forma, a relação entre leitura, contexto e interpretação (individual e coletiva) foi efetivada com o enriquecimento da leitura e, sobretudo, da compreensão do texto. $\mathrm{O}$ ato de relacionar o vocabulário específico de tal obra com uma abordagem lúdica permitiu o entendimento da narrativa de maneira eficiente e dinâmica.

$\mathrm{Na}$ finalização, os alunos produziram cartazes de propaganda sobre o livro trabalhado para que um mural de exposição fosse montado. E como última atividade, os discentes assistiram a trechos de documentários sobre a extração do látex e produção da borracha e da goma de mascar.

\section{ANÁLISES DAS PRODUÇÕES}

A seguir serão apresentadas as maneiras com as quais o texto literário foi trabalhado. Vale lembrar que o principal objetivo do trabalho é a prática de leitura, como seduzir o leitor levando-o ao prazer da leitura e avançar rumo ao letramento literário. A produção textual dos alunos foi, portanto, consequência natural da efetivação de uma boa leitura, da interiorização e humanização da narrativa, servindo de registro da prática aplicada.

\section{RESULTADOS DAS ATIVIDADES DESENVOLVIDAS}

As produções dos alunos foram variadas e criativas. Como atividade disparadora para o início do projeto (motivação), foram elaborados verbetes que narravam desde uma briga entre alunos por conta de um chiclete, passando por histórias de chicletes com sabor infinito até uma guerra entre Brasil e Paraguai causada por contrabando de chicletes e ambientada na Guerra do Paraguai, como se pode observar no texto abaixo: 
REVISTA X, Curitiba, volume 12, n.1, P. 160-177,2017.

\title{
A GUERRA DO CHICLETE
}

\author{
Miguel Sanches Neto \\ Prof. Rogério Nascimento Bortolin
}
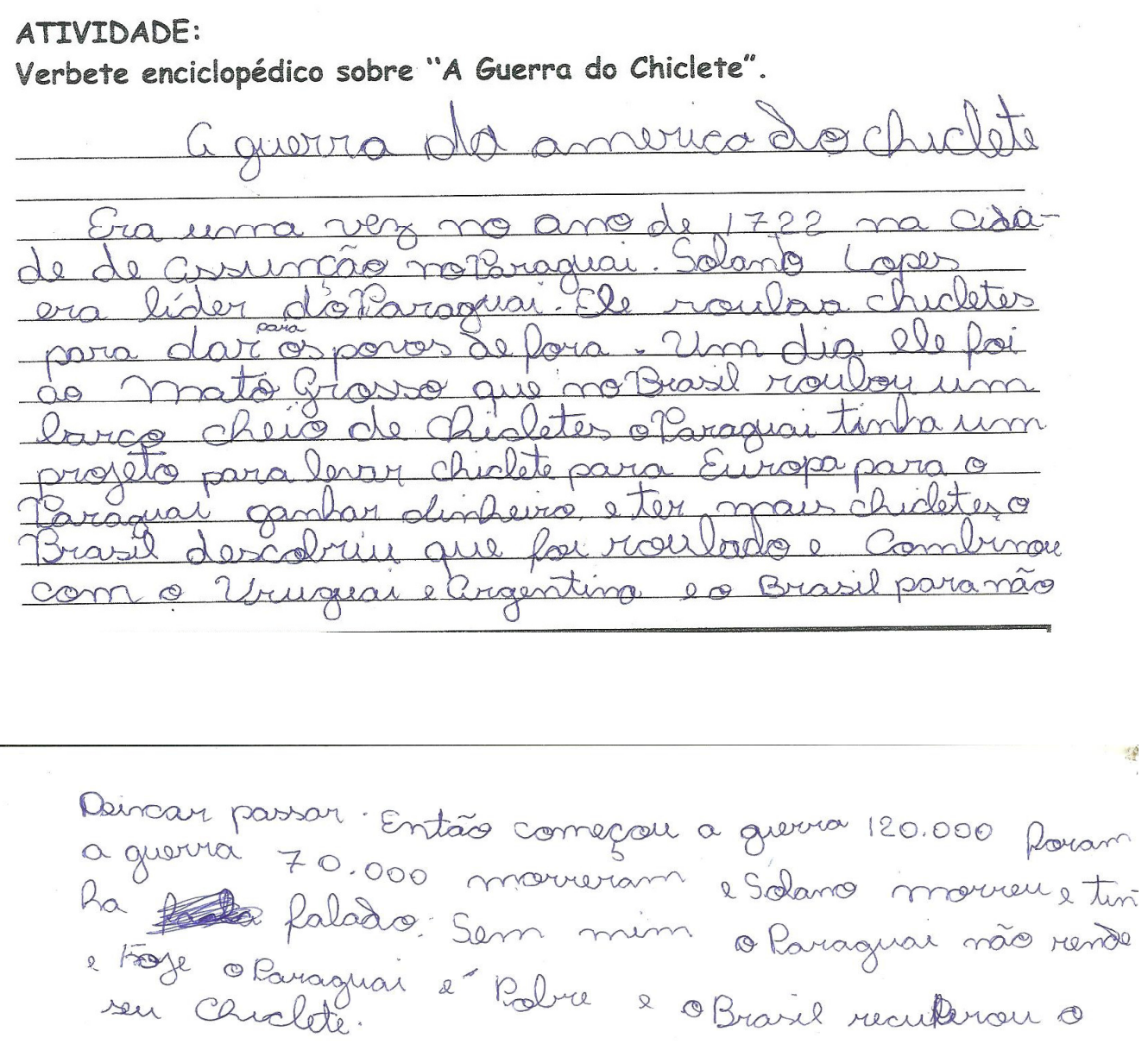

Primeira produção (motivação) Aluno X.

Esta foi a primeira versão do estudante. Os desvios da norma culta foram pontuados. O "erro" gramatical foi, portanto, um motivo para novas pesquisas, não um elemento punitivo, visto também que o mais importante para essa etapa era o conteúdo da produção e não a aplicação da formalidade da linguagem e do gênero textual, uma vez que pretende-se que o aluno domine ambas.

É possível notar que ele seguiu satisfatoriamente a estrutura do verbete de enciclopédia, visto que seu texto se enquadra nas características de tal gênero textual explicações e notas sobre determinado assunto ou "conjunto dos significados de uma palavra e exemplos de seu uso" (SOARES, 2011, p. 41), bem como respondeu às perguntas norteadoras para a produção de seu texto (supracitadas na descrição das atividades de motivação). A criatividade na escrita do estudante também chama a 
REVISTA X, Curitiba, volume 12, n.1, P. 160-177,2017.

atenção: não só transformou o tema Guerra do chiclete em fato histórico como recontextualizou a Guerra do Paraguai - incluindo a figura história de Solano López descrevendo as motivações criadas por ele para tal evento. Nos limites propostos por Cosson (2014) sobre motivação, a atividade proposta garantiu que os discentes pudessem, de maneira criativa e proativa, debruçar-se sobre a temática da obra, despertando, assim, o interesse pelo texto literário a ser trabalhado.

Como atividade de registro de leitura, os alunos também produziram cartazes (etapa final de todo o processo) fazendo propaganda do livro que leram e um mural foi montado na escola para que a exposição de tais textos se efetivasse. O registro escrito é uma maneira de expor e valorizar a obra enfocada e os textos produzidos, a partir dela, instigar novos leitores, além de inserir aqueles que tiveram contato com o livro em um contexto além dos limites da sala de aula.

Como última prática sobre a obra, os estudantes foram levados à sala de vídeo e assistiram a trechos de documentários sobre a extração do látex, a fabricação da borracha e dos chicletes, a fim de demonstrar de maneira real e concreta elementos presentes na narrativa. Eles ficaram surpresos em saber que a extração do látex, ainda nos dias de hoje, é feita de maneira bastante primitiva e admirados ao ver como as gomas de mascar são produzidas. Uma visita com os alunos a uma fábrica de doces da cidade também foi sugerida, no entanto, por questões de cronograma e segurança, a instituição entendeu como inviável naquele período, o que não se configurou necessariamente em uma lacuna na finalização do projeto, pois uma aula de vídeo para a apresentação de como é fabricada a goma de mascar foi efetivada, justamente prevendo tal possibilidade de impedimento de visita à fábrica.

Com base nos dados obtidos, as produções e a participação dos estudantes em todas as etapas desse projeto, é possível afirmar que foram alcançados resultados satisfatórios ao objetivo principal que se alicerçou e também quanto ao desenvolvimento de toda a prática aqui descrita e analisada, ou seja, promover o avanço rumo ao letramento literário dos alunos. $\mathrm{Na}$ realização dessa atividade, os alunos tiveram contato com uma obra literária, puderam interagir entre eles e discutir os efeitos de uma guerra em uma população, analisar e avaliar as atitudes das personagens frente aos desafios que lhes eram impostos, e principalmente, colocar-se no lugar delas e repensar suas atitudes em situações similares.

\section{CONSIDERAÇÕES FINAIS}


REVISTA X, Curitiba, volume 12, n.1, P. 160-177,2017.

Ler é fundamental para a sociedade, uma vez que nossas atividades mais rotineiras, como esperar um ônibus, comprar pão, ler bulas de remédio, entre outras, passam necessariamente pela escrita. Promover o letramento literário pressupõe na atividade de fomentar não apenas a decodificação textual, mas a identificação de um itinerário ou de uma palavra poética e também ser elemento transformador em sua vivência, ao promover a reflexão e potencializar a criticidade tornando a obra lida parte importante constituinte de seu acervo cultural.

Perante a demanda por um ensino significativo de literatura, a prática aqui exposta resulta numa alternativa eficiente, na medida em que permite ao leitor em formação ultrapassar a mera decodificação do texto literário, apropriando-se do conteúdo da obra, sendo capaz de expandir os sentidos do texto literário. A sequência básica colabora não somente com a formação do leitor, mas também com a formação do leitor literário.

Além disso, é necessário experimentar o prazer da leitura a partir das relações estabelecidas entre a obra e o mundo circundante, revelador dos aspectos sociais, históricos e culturais, proporcionando o acréscimo de outras competências que ampliem e aprimorem as suas competências de interação com o mundo e com o outro, promovidas por meio do letramento literário.

O trabalho com a literatura e o texto literário deve ser realmente tratado como uma experiência humanizadora. A literatura não é apenas o reflexo de uma sociedade por meio dos olhos de um autor. Ela não deve ser vista apenas como objeto de estudo histórico-social. Concordando aqui com Cândido, a literatura é indispensável para a humanização, pois ela atua no consciente e no subconsciente, retrata os costumes de uma sociedade, age como formadora da personalidade, leva o leitor à "fabulação", e, o mais importante: “A Literatura humaniza porque faz viver." (CANDIDO, 1995, p. 176).

Finalizada a abordagem instrumentalizada por meio da sequência básica apontada por Cosson (2014), foi possível verificar que o processo para o letramento literário obteve resultados satisfatórios e permitiu aos alunos o conhecimento da obra de um autor local, com enredo instigante e capaz de levar à reflexão de que pequenas atitudes podem ser propulsoras de grandes resultados. Avançando também rumo o letramento crítico, eles foram capazes de se colocar no lugar das personagens e levantar questionamentos pertinentes sobre distinções sociais e as relações de poder. 
REVISTA X, Curitiba, volume 12, n.1, P. 160-177,2017.

Pensar que o leitor apropriar-se-á de tal saber (ou de tal experiência) para assim transformar a realidade que o cerca parece algo utópico, porém se tomarmos essa transformação de início como pequenas mudanças na vida do leitor (um mau hábito que ele mude depois de ler um texto, a tomada de consciência e a humanização dele ao se colocar no lugar de um personagem e assim por diante), para só depois pensarmos em mudanças realmente grandes no meio que o cerca. Dessa forma, teríamos uma transformação que sairia do micro (indivíduo) para caminhar para o macro (meio). Esse é o real objetivo de se trabalhar a literatura e promover o letramento literário na sala de aula: humanizar os alunos, e é no campo das fabulações e no texto literário que encontramos um campo fértil e uma estratégia eficiente para que essa humanização se efetive, ou que no mínimo, possa avançar.

\section{REFERÊNCIAS}

AMAZON sat: Processo produtivo de borracha natural. Duração: 9:03 min. Disponível em: <https://www.youtube.com/watch?v=63yNzBMVpxc>. Acesso em: 1 maio 2016.

ANDRADE, Gabriel: Como é feita a goma de mascar o "chiclete”. Duração: 5:38 min. Disponível em: < https://www.youtube.com/watch?v=fTZ3FA-bFuo>. Acesso em: 1 maio 2016.

BRONCKART, Jean-Paul. Atividade de linguagem, discurso e desenvolvimento humano. Campinas: Mercado de Letras, 2006.

CANDIDO, Antonio. O direito à literatura. In: Vários escritos. São Paulo: Duas Cidades. 1995.p.

COSSON, Rildo. Letramento literário: teoria e prática. 2. ed. $3^{\text {a }}$ reimpressão. São Paulo: Contexto, 2014.

MARCUSCHI, Luiz Antônio. Produção textual, análise de gêneros e compreensão. São Paulo: Parábola Editorial, 2008.

SANCHES NETO, Miguel. A guerra do chiclete. 2 ed. Curitiba: Positivo, 2014.

SOARES, Rosalina Mariana Rathlew. Língua Portuguesa: $6^{\circ}$ ano. Curitiba: Positivo, 2011.

TINOCO, Robson Coelho. Percepção do mundo na sala de aula: leitura e literatura. In: DALVI, Maria Amélia; REZENDE, Neide Luzia de; JOVER-FALEIROS, Rita (Orgs.). Leitura de Literatura na Escola. São Paulo: Parábola, 2013. p.135 - 15

WELLEK, René; WARREN, Austin. Natureza da literatura. In: Teoria da Literatura. 5. ed. Sintra: Europa - América, 1974. p. 24. 


\title{
APÊNDICE
}

\section{A Guerra do Chiclete}

Miguel Sanches Neto

Encontre as palavras do quadro abaixo no caça-palavras

\author{
AMAZÔNIA BATALHÃO-DA-BORRACHA BORRACHA CHICLETE LÁTEX \\ COCA-COLA ESTADOS-UNIDOS EXÉRCITO GUERRA REVOLUÇÃO RUMINANTE \\ SACRIFÍCIO SERINGUEIRA SERINGUEIRO SOLDADO
}

B Y YE OEA VYROXITKABEPVZVKHG GASGAHRSTXEHGZASVOQZFIPFL FOTQCKRYMTNBLDQXPZRNDJLCW ZEKAUSEJASWIVMJTBTBRJFEBR PKOWLDULWFXKDOVXAAGKAMYBT I UNTOHGNWMKKEXGMISAHECZRU BMRKVIÃOKWEJYNZCTLHFFFHWZ MTHQEAZOMPNLJOBYOYWPFRDAJ MNEARNMEDBGDASRCGPFUEDZMF DXJDWLVSRATOQAARUMINANTEC FDSDWGKTDTBIDCIJLCKWWPDMH AINÔZAMACYIOOAPVPUXWYXNRI VJEUNNADQDQCRGDJSPINITFBC RDXNOTNOTFGZLRYLXTHFEQBGL WKZAJZJSTRSRHDAHOQMXTEBGE KKAQZXEUNEMFBKOCFSÉXLELWT WDADRKKNRRCKBUNIHR VWMKPWE DWDILORIEUGNIRESCACGASNOR G OVWAONDFWSTXZWIXÍXDJSZPB VHWUZGSOERKSTNTWUBFJNIYDA UZBHUXFSASAUQOEEBYFIEWISB LKNEVYNLLYESZOAIAG VURMPTG NOIDSQTBPHERIOBIRYAGQCVKL GRQAOHVZJCRTKELTOJAVKXAJD A LFTLNGSHYEQW JTMSDVOZXC 
REVISTA X, Curitiba, volume 12, n.1, P. 160-177,2017.

ANEXOS

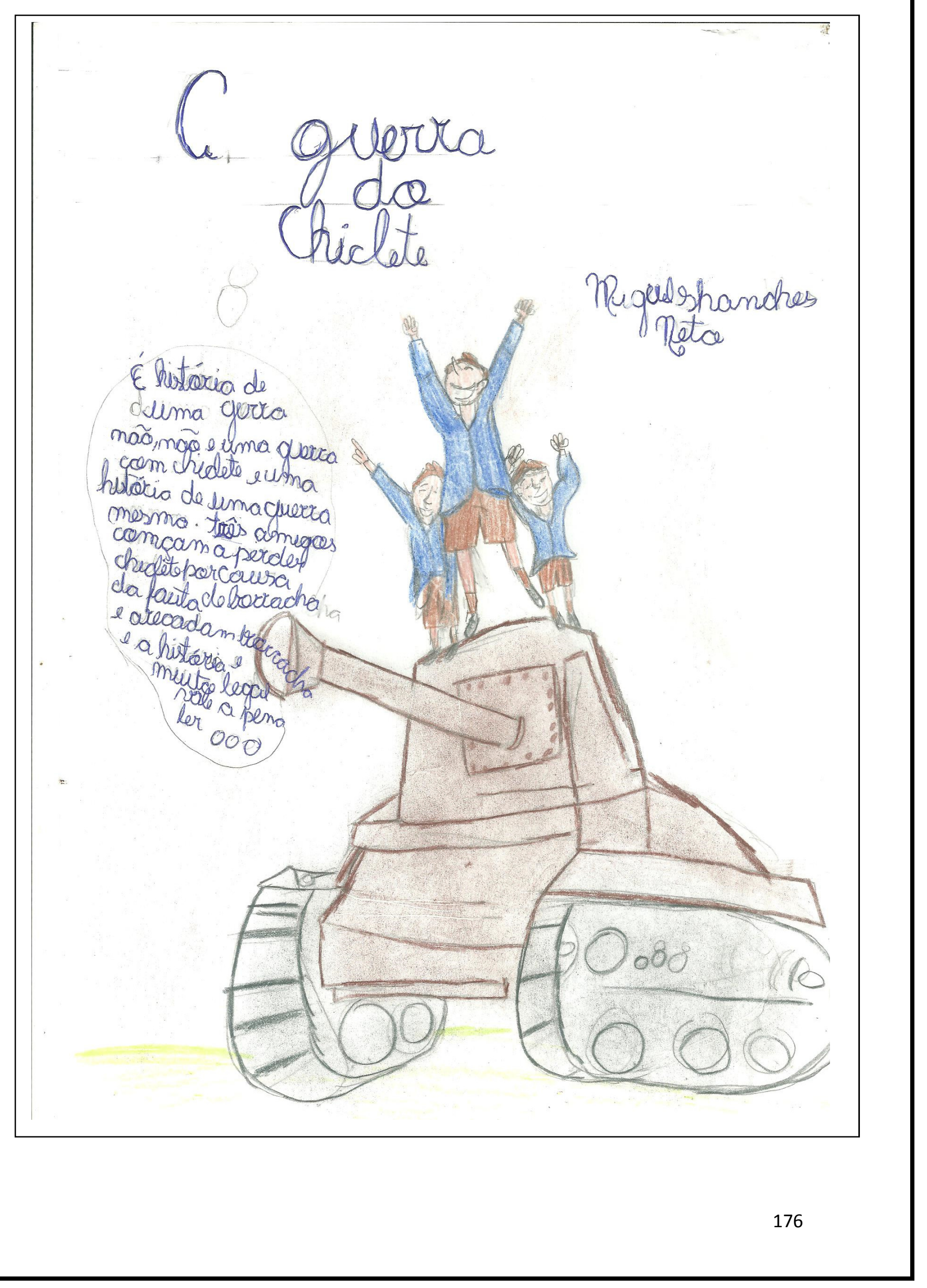


REVISTA X, Curitiba, volume 12, n.1, P. 160-177,2017.

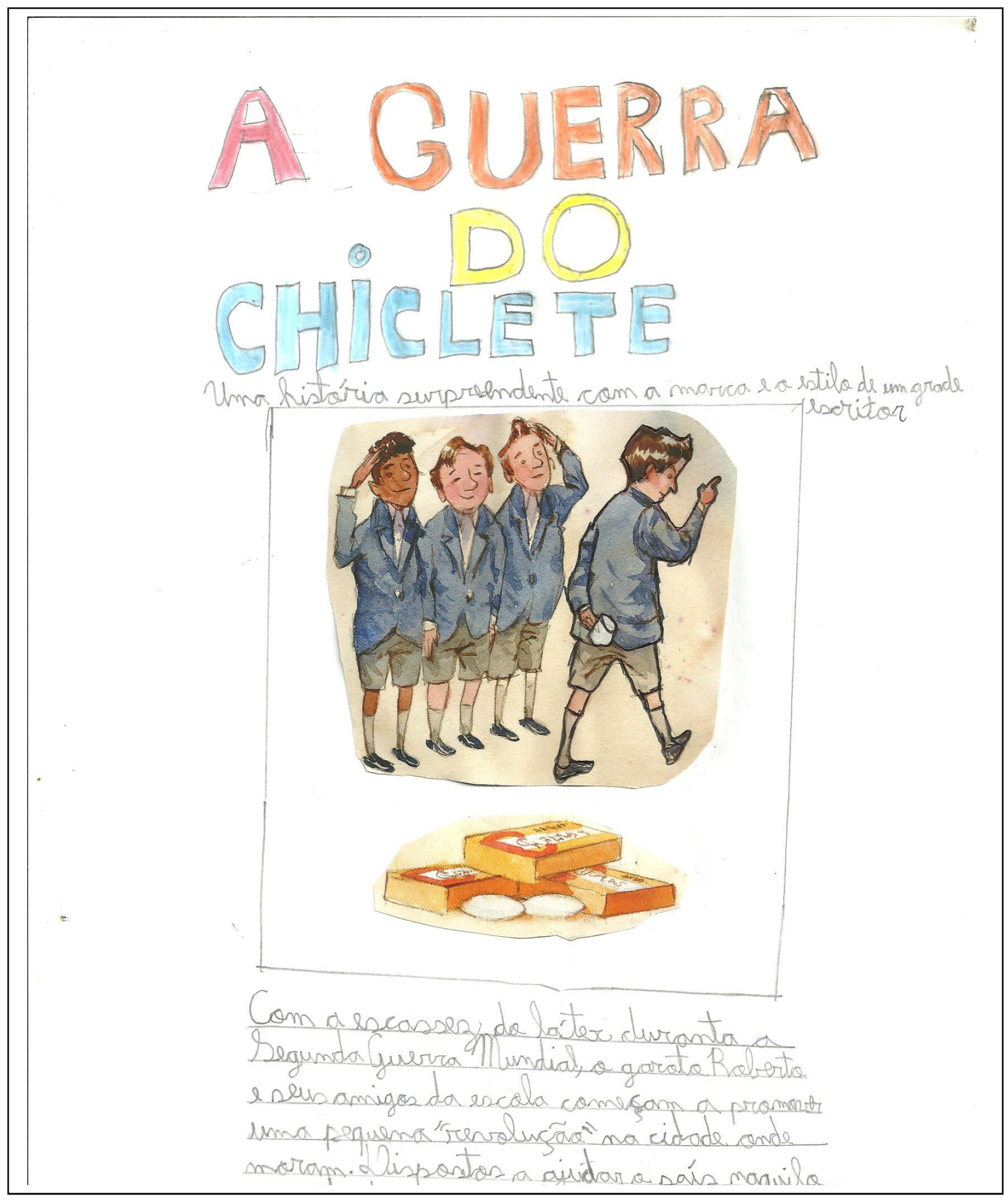

* Desvios da norma padrão culta no texto do aluno foram sinalizadas e alteradas por ele, a versão aqui disponível é a primeira versão do texto sem as correções aopntadas. 